\title{
Studies on blood lymphocytes of patients with nodular poorly differentiated lymphocytic lymphoma
}

\author{
AS KRAJEWSKI, AE DEWAR \\ From the Department of Pathology, University Medical School, Teviot Place, Edinburgh
}

SUMMARY T and B lymphocytes were measured in pretreatment blood samples from patients with? nodular poorly differentiated lymphocytic lymphoma (NPDLL). There were significant differences $\omega_{+}^{\omega}$ in T cell values between control groups and patients with NPDLL. In 13 out of 20 cases of NPDLL $\infty^{\circ}$ blood lymphocytes showed abnormalities of immunoglobulin light chain expression and were $\mathscr{\infty}_{0}^{\infty}$ considered to show an abnormal clonal expansion of B lymphocytes. The abnormal clone of B cellso in the blood reflected that found in lymph nodes and could be detected in the absence of bone marrow ${ }_{-}^{\supset}$ involvement or blood lymphocytosis.

The B cell origin of the majority of non-Hodgkin's lymphomas (NHL) has been established using surface markers. ${ }^{1-3}$ In most cases the investigations into the circulating cells in these patients have been incidental to the studies on the tumour cells from solid tissues. ${ }^{4-7}$ Garrett et al. ${ }^{8}$ reported that the blood lymphocytes of many patients with NHL had detectable abnormalities of surface immunoglobulin light or heavy chain expression; but the numbers of each sub-type of NHL in this series were small. Ligler et al. ${ }^{9}$ found that seven out of eight cases of NHL had detectable abnormalities in surface immunoglobulin in the circulating B cell population.

This paper describes the results of investigations into the peripheral blood lymphocyte subpopulations in cases of nodular poorly differentiated lymphocytic lymphoma (NPDLL). The findings are correlated with clinical stage and, in some cases, with laboratory studies on tumour tissue.

\section{Material and methods}

Solid tumour samples, mainly lymph nodes, were obtained as fresh specimens from surgical theatres in hospitals in the Lothian Region. Blood samples were taken either just before biopsy or 2 weeks after biopsy. All blood samples were taken pretreatment. The control material in this study consisted of samples of lymph node tissue and blood from patients who were found not to have lymphoma -for example, reactive hyperplasia, toxoplasmosis, carcinoma etc. Patients histologically diagnosed as

Accepted for publication 9 February 1981 nodular lymphoma were staged according to Ann- $\overrightarrow{-}$ Arbor classification and grouped as either stage I-IIIOO or stage IV. Cell suspensions were obtained fromlymph nodes and peripheral blood as previouslyo described. 1011

Lymph nodes were teased into TC 199 (Flowō Laboratories, Irvine, Ayrshire) and washed once⿳ू๊ before surface marker studies. Blood mononuclearo cells were isolated using Ficoll/Hypaque and washed $\overrightarrow{0}$ twice before use. In surface marker studies we used 3 sheep erythrocyte rosettes to identify the $T$ cell? population. B cells were counted by means of an: indirect fluorescence method on mononuclear cells which had been incubated in serum-free medium for:$45 \mathrm{~min}$ at $37^{\circ} \mathrm{C}$ and then washed for a third time. Unconjugated rabbit antisera to human sera, kappa and lambda chains were obtained from Nordic옥 Immunologic Laboratories. The sera were adsorbed for $30 \mathrm{~min}$ at $37^{\circ} \mathrm{C}$ with washed human erythrocytes before ultracentrifugation at $150000 \mathrm{~g}$ for $40 \mathrm{~min}$, $\frac{D}{0}$ aliquoting, and storage at $-70^{\circ} \mathrm{C}$. Goat anti-rabbit IgG conjugated with FITC, from the same source, $/ \mathcal{N}$ was also ultracentrifuged before storage at $-70^{\circ} \mathrm{C}$. $N$ $3-5 \times 10^{6}$ cells were incubated for $10 \mathrm{~min}$ at $37^{\circ} \mathrm{C}$ in the appropriate dilution of specific antiserum, $\omega$ washed once in $10 \mathrm{ml}$ phosphate buffered saline(PBS) then incubated in the FITC conjugate for $20 \mathrm{~min}$ on ice, washed once in $10 \mathrm{ml}$ PBS and examined under $\mathbb{\Phi}$ ultraviolet illumination on a Leitz Orthomat with $?_{+}^{+}$ incident illumination.

We used immunoperoxidase techniques to demon- $\frac{\mathrm{O}}{\mathrm{D}}$ strate the monoclonality of the tumour in paraffin $\frac{?}{\mathbb{Q}}$ sections of the lymph nodes, as described by Burns. ${ }^{12} \stackrel{\mathbb{}}{ }$ Sections were stained for IgM heavy chain and kappa? 
Table 1 Percentage and total number of $T$ cells in the blood of patients with NPDLL at stages I, II, and III

\begin{tabular}{|c|c|c|c|c|c|}
\hline Case No & Total $w b c \times 10^{9} / 1$ & $\%$ lymphocytes & Total lymphoctyes $\times \cdot 10 / l$ & $\% T$ cells & Total T cells $\times 10^{\%} / l$ \\
\hline 1 & 3.00 & 5 & 0.20 & 39.0 & 0.075 \\
\hline 2 & $7 \cdot 30$ & 9 & 0.66 & $23 \cdot 5$ & 0.153 \\
\hline 3 & $4 \cdot 2$ & 16 & 0.67 & $61 \cdot 5$ & 0.412 \\
\hline 4 & $2 \cdot 4$ & 29 & 0.69 & $47 \cdot 5$ & 0.331 \\
\hline 5 & $4 \cdot 4$ & 16 & $0 \cdot 70$ & $60 \cdot 0$ & 0.423 \\
\hline 6 & $6 \cdot 0$ & 16 & 0.96 & $45 \cdot 0$ & 0.432 \\
\hline 7 & $5 \cdot 2$ & 20 & 1.00 & $38 \cdot 0$ & 0.395 \\
\hline 8 & 4.4 & 25 & $1 \cdot 10$ & $72 \cdot 0$ & 0.790 \\
\hline 9 & 3.9 & 31 & $1 \cdot 20$ & $34 \cdot 5$ & 0.415 \\
\hline 10 & $4 \cdot 2$ & 37 & 1.55 & $57 \cdot 0$ & 0.887 \\
\hline 11 & $12 \cdot 6$ & 13 & 1.64 & 56.5 & 0.924 \\
\hline 12 & $5 \cdot 0$ & 34 & 1.74 & $41 \cdot 0$ & 0.698 \\
\hline 13 & $14 \cdot 4$ & 12 & 1.73 & 41.5 & 0.719 \\
\hline 14 & $7 \cdot 5$ & 34 & $2 \cdot 50$ & $34 \cdot 5$ & 0.878 \\
\hline 15 & $7 \cdot 7$ & 36 & $2 \cdot 54$ & $42 \cdot 5$ & 1.079 \\
\hline
\end{tabular}

Conversion: SI to traditional units $-1 \times 10^{\circ} / \mathrm{l}=1000 / \mathrm{mm}^{3}$.

Table 2 Percentage and total number of $T$ cells in the blood of NPDLL patients with stage IV disease

\begin{tabular}{|c|c|c|c|c|c|}
\hline Case No & Total $w b c \times 10^{9} / l$ & $\%$ lymphocytes & Total lymphocytes $\times 10^{9} / \mathrm{l}$ & $\% T$ cells & Total T cells $\times 10^{\%} / \mathrm{l}$ \\
\hline 16 & 4.5 & $7 \cdot 0$ & $0 \cdot 31$ & $5 \cdot 0$ & 0.015 \\
\hline 17 & $7 \cdot 3$ & $5 \cdot 0$ & $0 \cdot 36$ & $18 \cdot 5$ & 0.067 \\
\hline 18 & $3 \cdot 1$ & $17 \cdot 0$ & 0.53 & $28 \cdot 0$ & $0 \cdot 148$ \\
\hline 19 & 3.5 & 18.0 & 0.63 & $20 \cdot 0$ & 0.126 \\
\hline 20 & $3 \cdot 2$ & 24.0 & 0.77 & $63 \cdot 0$ & 0.483 \\
\hline 21 & $8 \cdot 8$ & $10 \cdot 0$ & 0.88 & $39 \cdot 5$ & 0.347 \\
\hline 22 & $2 \cdot 4$ & 40.0 & 0.96 & $28 \cdot 5$ & 0.274 \\
\hline 23 & 6.0 & $19 \cdot 0$ & $1 \cdot 10$ & $41 \cdot 0$ & 0.470 \\
\hline 24 & $5 \cdot 5$ & $24 \cdot 0$ & $1 \cdot 30$ & $49 \cdot 5$ & 0.651 \\
\hline 25 & $6 \cdot 3$ & $20 \cdot 0$ & $1 \cdot 30$ & $23 \cdot 5$ & 0.295 \\
\hline 26 & $6 \cdot 5$ & $20 \cdot 0$ & $1 \cdot 30$ & $18 \cdot 5$ & 0.239 \\
\hline 27 & $6 \cdot 0$ & $25 \cdot 0$ & 1.50 & $33 \cdot 0$ & 0.495 \\
\hline 28 & $5 \cdot 2$ & 30.0 & 1.56 & 8.0 & $0 \cdot 125$ \\
\hline 29 & $5 \cdot 3$ & $33 \cdot 0$ & 1.70 & 30.0 & 0.524 \\
\hline 30 & $8 \cdot 1$ & $73 \cdot 0$ & 5.90 & $7 \cdot 0$ & 0.404 \\
\hline 31 & $7 \cdot 4$ & $81 \cdot 0$ & 6.00 & $23 \cdot 0$ & $1 \cdot 378$ \\
\hline 32 & $12 \cdot 0$ & $62 \cdot 0$ & $7 \cdot 40$ & $21 \cdot 5$ & 1.608 \\
\hline 33 & $13 \cdot 8$ & $67 \cdot 0$ & $9 \cdot 20$ & $19 \cdot 5$ & 1.746 \\
\hline 34 & $12 \cdot 0$ & $80 \cdot 0$ & $9 \cdot 60$ & 21.0 & 2.000 \\
\hline 35 & 14.9 & $66 \cdot 0$ & $9 \cdot 80$ & 15.0 & 1.499 \\
\hline 36 & $34 \cdot 0$ & 95.0 & $32 \cdot 30$ & $15 \cdot 5$ & 5.020 \\
\hline 37 & 103.0 & 91.0 & $93 \cdot 70$ & 6.5 & 6.092 \\
\hline 38 & 117.0 & $100 \cdot 0$ & 117.00 & 6.5 & 6.436 \\
\hline
\end{tabular}

and lambda light chains. Blood films, stained with May-Grünwald-Giemsa, were used for routine differential counts and examined for the presence of morphologically abnormal circulating cells.

\section{Results}

T CELLS IN BLOOD

The results in Tables 1 and 2 show that of 38 cases of NPDLL, 13 had low lymphocyte counts $\left(<1 \times 10^{9} / 1\right.$ $\left.\left(<1000 / \mathrm{mm}^{3}\right)\right)$ at time of presentation, six had lymphocytosis (between 5-10 $\times 10^{9} / 1\left(5-10000 / \mathrm{mm}^{3}\right)$ whilst three were frankly leukaemic (more than $10 \times 10^{9} / 1\left(>10000 / \mathrm{mm}^{3}\right)$ ). All groups of patients had significantly lower percentages of $T$ cells than normal donors or patients with non-lymphomatous lymphadenopthy (Student's $t$ test $\mathrm{p}<0.0005$ ). There were no significant differences in percentages of $T$ lymphocytes between patients with low and normal lymphocyte counts in either the stage I-III or the stage IV groups.

There was a significant difference $(p<0.0005)$ between the group stage I-III and stage IV (Fig. 1). Only one of the patients in stage I-III group (Table 1, Case 2) had less than $35 \% \mathrm{~T}$ cells, whilst $10 / 14$ with stage IV (but without lymphocytosis) had less than $35 \% \mathrm{~T}$ cells. All the patients with either lymphocytosis or leukaemia had bone marrow involvement and a reduced percentage of $T$ cells.

The results of absolute $T$ cell numbers are summarised in Fig. 2. They were essentially similar to those shown in Fig. 1, except that stage I-III patients with low lymphocyte counts were $\mathrm{T}$ cell depleted, and patients with lymphocytosis had, in absolute terms, 


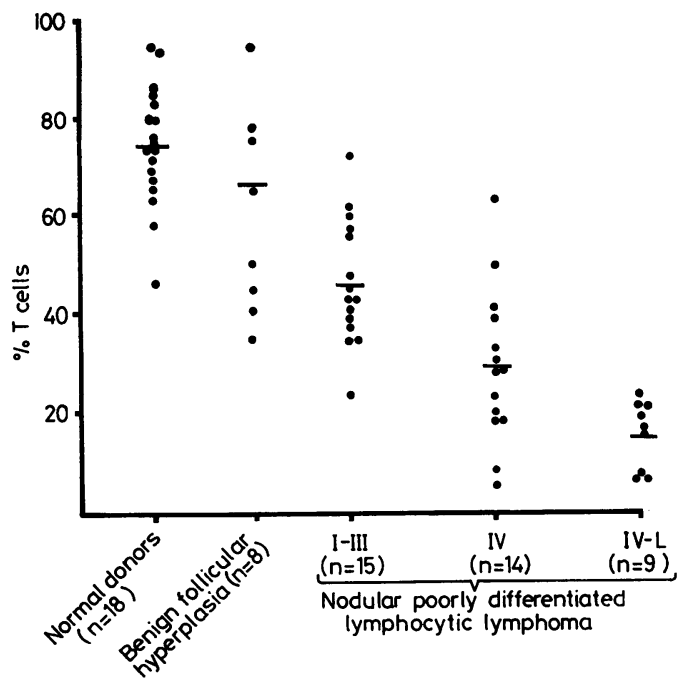

Fig. 1 Percentage $T$ cells in the blood of NPDLL patients. $n=$ number of cases in each group, ${ }^{-}=$mean, - = individual value. Stage IV cases had normal lymphocyte counts; Stage IV-L cases had lymphocytosis.

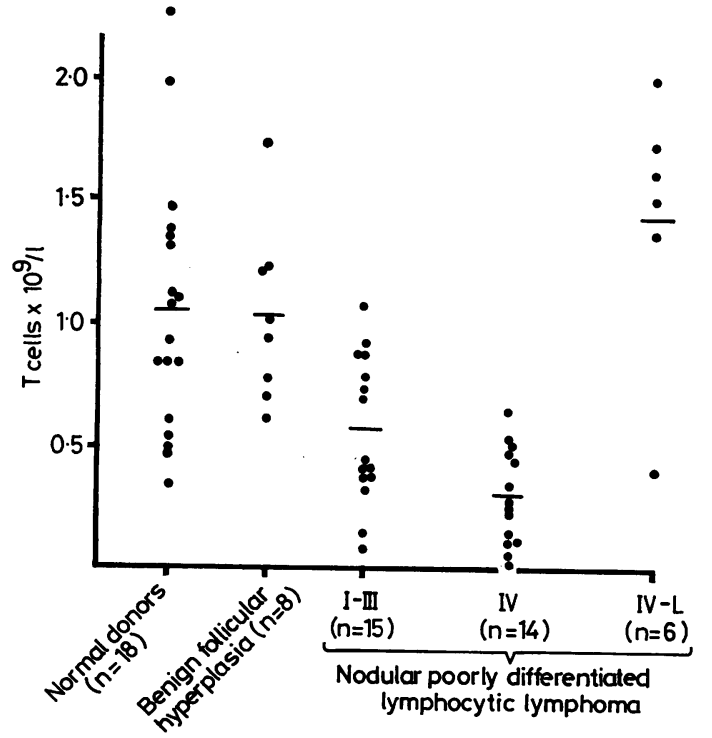

Fig. 2 Percentage $T$ cells in the blood of NPDLL patients. $n=$ number of cases in each group, $-=$ mean, - individual value. Stage IV cases had normal lymphocyte counts; stage IV-L cases had lymphocytosis excluding three leukaemic cases with $T$ cell counts $>5.0 \times 10^{\circ} / \mathrm{l}\left(>5000 / \mathrm{mm}^{3}\right)$.

significantly raised numbers of $T$ cells.

B CELl POPUlation IN NPDLL Light chain expression on the circulating B cells in normal individuals has a constant pattern; with a $\stackrel{\mathrm{O}}{.}$ kappa:lambda $(\kappa: \lambda)$ ratio of about $3: 2$. In 28 blood $\overrightarrow{\bar{F}}$ samples from patients with non-lymphomatous lymphadenopathy (12 samples) and normal donors (16 samples) the mean $\kappa: \lambda$ ratio was 1.48 with an upper limit (mean $+2 \mathrm{SD}$ ) of 2.75 and the mean lambda:kappa $(\lambda: \kappa)$ ratio was 0.78 with an upper $\varrho$ limit of 1.35 (mean +2 SD). Ratios above these \& limits were considered to indicate a monoclonal $\vec{\circ}$ expansion of lymphocytes with either kappa $(\kappa: \lambda>2.75)$ or lambda $(\lambda: \kappa>1.35)$ light chain. Only $\vec{\omega}$ one of the 28 non-lymphoma cases (donor attending blood transfusion centre, no repeat sample available) ? had an abnormal ratio according to these criteria, $\omega$ whilst 9/20 NPDLL patients had an abnormal $\kappa: \lambda \dot{0}$ ratio and $5 / 20$ had an abnormal $\lambda: \kappa$ ratio. Abnormal blood light chain ratios were found in $5 / 6$ cases without bone marrow involvement and in 9/13 cases with bone marrow involvement. In 11 cases abnormal $\kappa: \lambda$ or $\lambda: \kappa$ ratios were found in the absence of morphologically abnormal lymphocytes in routinely-stained peripheral blood films. In three cases with abnormal light chain ratios morphologically abnormal cells were seen in blood films.

Light chain expression on lymph nodes were studied by means of indirect fluorescence on cell suspension. In lymph nodes from 27 patients with non-lymphomatous conditions, the mean $\kappa: \lambda$ ratio was 1.54 with an upper limit (mean +2 SD) of 3.4 and the mean $\lambda: \kappa$ ratio was 0.86 with an upper limit (mean +2 SD) of $1 \cdot 70$. Only one of the 27 cases had an abnormal ratio according to these criteria. This was a lymph node showing the features of dermatopathic lymphadenopathy with no evidence of lymphoma. Immunofluorescent studies were carried out on lymph nodes in 11 NPDLL patients; five cases showed an abnormal $\kappa: \lambda$ ratio and one case an abnormal $\lambda: \kappa$ ratio, the remaining five cases showed normal proportion of kappa- and lambda-bearing lymphocytes. In the cases with monoclonal expansion the abnormality was consistent with that found in blood. In none of our cases did we detect one light chain in the blood and the other in the lymph nodes (Table 3).

Immunoperoxidase-stained sections were examined in 19/20 NPDLL cases. In eight cases there was definite evidence of monoclonal cytoplasmic light chain expression. Other cases showed either a polyclonal staining pattern or were negative. In cases with a monoclonal staining pattern the abnormality was consistent with immunofluorescence findings in blood and lymph node cell suspensions (Table 3 ).

In five cases of NPDLL, blood samples were obtained both before and after treatment. Results of receptor studies on blood are shown in Table 4. In three cases $(12,27$ and 35) abnormal $\kappa: \lambda$ or $\lambda: \kappa$ ratios 
Table 3 Light chain expression in blood and lymph nodes of NPDLL patients

\begin{tabular}{|c|c|c|c|c|c|}
\hline \multirow[t]{2}{*}{ Case No } & \multicolumn{3}{|c|}{ Blood mononuclear cells } & \multicolumn{2}{|l|}{ Lymph node } \\
\hline & $\kappa: \lambda$ & $\lambda: \kappa$ & Morphologically abnormal lymphocytes & Immunofluorescence & Immunoperoxidase \\
\hline \multicolumn{6}{|c|}{ Stage I-III } \\
\hline 3 & 1.50 & 0.67 & $\mathbf{A}$ & Polyclonal & $\mathbf{M} \kappa$ \\
\hline 7 & 0.66 & 1.52 & $\mathbf{A}$ & - & $\lambda$ \\
\hline 8 & 9.00 & $0 \cdot 11$ & $\mathbf{A}$ & $\kappa$ & $\ddot{\mathbf{M}}_{\kappa}$ \\
\hline 12 & 0.32 & 3.08 & $\mathbf{A}$ & - & $\mathbf{M} \kappa \lambda$ \\
\hline 13 & 2.57 & $0 \cdot 39$ & $\mathbf{A}$ & $\kappa$ & neg \\
\hline 39 & 0.71 & 1.40 & $\mathbf{A}$ & Polyclonal & $\mathbf{M} \lambda$ \\
\hline 15 & 3.60 & $0 \cdot 28$ & $\mathbf{A}$ & - & $\mathbf{M} \kappa \lambda$ \\
\hline \multicolumn{6}{|l|}{ Stage IV } \\
\hline 16 & 0.92 & 1.09 & $\mathbf{P}$ & - & $\kappa \lambda$ \\
\hline 17 & 4.09 & 0.24 & $\mathbf{A}$ & $\kappa$ & $\kappa$ \\
\hline 20 & $7 \cdot 20$ & $0 \cdot 14$ & $\mathbf{A}$ & - & $\kappa$ \\
\hline 23 & 3.03 & 0.33 & $\mathbf{A}$ & Polyclonal & $\mathbf{M} \kappa \lambda$ \\
\hline 24 & 0.58 & 1.72 & $\mathbf{A}$ & - & M \\
\hline 26 & 8.60 & 0.12 & $\mathbf{A}$ & - & $\mathbf{M} \kappa$ \\
\hline 27 & 4.00 & 0.25 & $\mathbf{A}$ & - & neg \\
\hline 28 & $1 \cdot 46$ & 0.68 & $\mathbf{A}$ & $\lambda$ & neg \\
\hline 30 & $2 \cdot 14$ & 0.47 & $\mathbf{P}$ & Polyclonal & neg \\
\hline 31 & 1.21 & 0.83 & $\mathbf{P}$ & Polyclonal & - \\
\hline 33 & $6 \cdot 75$ & $0 \cdot 15$ & $\mathbf{P}$ & $\kappa$ & $\mathbf{M} \kappa$ \\
\hline 35 & $21 \cdot 0$ & 0.05 & $\mathbf{P}$ & $\kappa$ & $\mathbf{M}$ \\
\hline 36 & $0 \cdot 17$ & $5 \cdot 8$ & $\mathbf{P}$ & - & $\mathbf{M} \kappa \lambda$ \\
\hline Normal & $<2.75$ & $<1 \cdot 35$ & - & Polyclonal & $\mathbf{M} \kappa \lambda$ \\
\hline
\end{tabular}

Abnormal $\kappa: \lambda$ or $\lambda: \kappa$ ratios are in italic.

$\mathbf{P}=$ present

$A=$ absent.

M = IgM heavy chain; $\kappa=$ kappa light chain; $\lambda=$ lambda light chain; - the last two columns in the table illustrate their distribution in lymph nodes as detected by immunofluorescence or immunoperoxidase staining.

Table 4 Immunological findings in the blood of patients with NPDLL at diagnosis and after treatment

\begin{tabular}{|c|c|c|c|c|c|c|c|c|c|}
\hline Case No & Months since diagnosis & $w b c\left(\times 10^{9} / l\right)$ & $\%$ lymphocytes & $\% T$ & $\%$ SIg & $\% \kappa$ & $\% \lambda$ & $\kappa: \lambda$ & $\lambda: \kappa$ \\
\hline \multirow[t]{2}{*}{12} & 0 & $5 \cdot 0$ & 34 & 41 & 33 & 13 & 40 & $0 \cdot 33$ & 3.08 \\
\hline & 4 & 4.9 & 19 & 74 & 61 & 14 & 42 & 0.33 & 3.00 \\
\hline \multirow{2}{*}{27} & 0 & $6 \cdot 0$ & 25 & 33 & 66 & 52 & 13 & 4.00 & 0.25 \\
\hline & 5 & $6 \cdot 0$ & 3 & 10 & - & 68 & 18 & $3 \cdot 78$ & 0.24 \\
\hline \multirow{2}{*}{28} & 0 & $5 \cdot 2$ & 30 & 8 & 71 & 51 & 35 & 1.46 & 0.68 \\
\hline & 9 & $8 \cdot 3$ & 20 & 13 & 46 & 34 & 14 & $2 \cdot 43$ & 0.41 \\
\hline \multirow[t]{2}{*}{35} & 0 & 14.9 & 66 & 15 & 49 & $73 \cdot 5$ & 3.5 & $21 \cdot 0$ & 0.05 \\
\hline & 12 & $4 \cdot 9$ & 66 & 9 & 64 & 43.0 & $13 \cdot 0$ & $3 \cdot 3$ & 0.30 \\
\hline \multirow{2}{*}{36} & 0 & $34 \cdot 0$ & 95 & 15 & 58 & 8 & 46 & $0 \cdot 17$ & $5 \cdot 8$ \\
\hline & 12 & 3.6 & 24 & 65 & - & 14 & 20 & $0 \cdot 70$ & 1.43 \\
\hline
\end{tabular}

T cells were identified by rosetting with sheep red blood cells. B cells were identified by immunofluorescence with anti-human IgM (SIg) heavy chain and anti-human kappa $(\kappa)$ and lambda $(\lambda)$ light chain antisera.

Abnormal $\kappa: \lambda$ and $\lambda: \kappa$ ratios are in italic.

persisted despite treatment. Case 28 with a normal ratio, remained normal. In case 36 , a patient who presented with a leukaemic blood picture and an abnormal $\lambda: \kappa$ ratio, treatment resulted in restoration of white cell count to normal, however the abnormal $\lambda: \kappa$ ratio persisted.

\section{Discussion}

Although abnormalities in the numbers of blood $\mathrm{T}$ cells in nodular lymphoma have previously been reported, ${ }^{13}$ a correlation between percentage or absolute $\mathrm{T}$ cell counts and clinical stage has not been recognised. Our results suggest that blood $T$ cell studies are of value in assessing the extent of disease and may be a useful addition to conventional staging procedures-for example, bone marrow biopsy, lymphangiography. At present the relation between blood $T$ cell counts, prognosis, and response to treatment is unknown but we suggest that reduction of blood T cells may reflect extensive or "bulky" disease. This is of clinical relevance as disease "bulk" appears to be a major prognostic factor in nodular lymphoma. ${ }^{14}$

The finding of an abnormal distribution of immunoglobulin light chains on blood lymphocytes 
in nodular lymphoma is consistent with a previous report by Garrett ${ }^{8}$ who found five out of 16 cases of nodular lymphoma with abnormal $\kappa: \lambda$ ratios. However in Garrett's series only one of 11 cases of NPDLL showed blood abnormalities, the other four cases with abnormal blood $\kappa: \lambda$ ratios were cases of nodular well-differentiated lymphocytic lymphomas. In the present study 14 of 20 cases of NPDLL were considered to show abnormalities of $\kappa: \lambda$ ratios indicating an expanded monoclonal $B$ cell population in blood. Abnormalities of light chain expression were found in the absence of either morphologically abnormal cells or lymphocytosis. Surprisingly two cases with lymphocytosis showed normal $\kappa: \lambda$ ratios although $\mathbf{B}$ cells were increased and numerous cleaved cells were present. Failure to detect a monoclonal expansion in these cases was presumably due to adsorbed immunoglobulin on cell membranes, possibly bound by $\mathrm{Fc}$ receptors. ${ }^{15}$

Immunological studies on lymph nodes were carried out to determine whether abnormalities of immunoglobulin light chain expression on circulating B lymphocytes correspond to that seen in lymph nodes. In 11 cases we were able to demonstrate monoclonal light chain expression in lymph nodes, in the other 9 cases failure to detect monoclonality may have been due to adsorbed surface immunoglobulin or other methodological difficulties in immunofluorescence and immunoperoxidase staining. ${ }^{16} 17$ In cases in which monoclonality was demonstrated both in lymph nodes and blood the same light chain was abundant in both indicating that cells in blood were of the same clonal origin as neoplastic cells in nodes.

It seems probable that technical difficulties in establishing monoclonality of blood lymphocytes in lymphoma with conventional immunofluorescence procedures leads to an underestimate of cases with monoclonality, and it may be possible to demonstrate a higher incidence of monoclonality in blood of lymphoma patients with more sophisticated techniques such as analysis by a fluorescent-activated cell sorter as described by Ligler. ${ }^{9}$ Nevertheless, on conventional immunofluorescence microscopy we were able to detect abnormalities in a high proportion of cases of lymphoma, indicating that simple immunofluorescence is still a useful diagnostic procedure.

In five cases in which follow-up blood samples were examined, abnormalities of light chain ratios persisted in four cases despite an apparently satisfactory response to treatment. Although the significance of these findings is at present not known, it is possible that examination of sequential blood samples for evidence of abnormalities of light chains on lymphocytes may provide a method for monitor- ing the effect of treatment.

We are grateful to the physicians and surgeons of the Edinburgh Lymphoma Group for clinical material used in this study. The work was done under the auspices of the Edinburgh Lymphoma Group in the Department of Pathology, University of Edinburgh. The authors are indebted to Miss EF Ramage, Miss \& J Kidby and Mr RM Hogg for their expert technical assistance.

\section{References}

${ }^{1}$ Lukes RJ, Taylor CR, Parker JW, Lincoln TL, Pattengale PK, Tindle BH. A morphologic and immunologic $\underset{f}{\infty}$ surface marker study of 299 cases of non-Hodgkin's $\infty$ lymphomas and related leukaemias. Am J Pathol 1978; 90:461-86.

2 Pinkus GS, Said JW. Characterization of non-Hodgkin's lymphomas using multiple cell markers: immunologic, morphologic and cytochemical studies of 72 cases. $\mathrm{Am} \mathrm{J}$ Pathol 1979;94:349-76.

${ }^{3}$ Habeshaw JA, Catley PF, Stansfeld AG, Brearley RL. Surface phenotyping, histology and the nature of $\frac{C}{\omega}$ non-Hodgkin's lymphoma in 157 patients. $\mathrm{Br} J$ Cancer 1979;40:11-34.

${ }^{4}$ Gajl-Peczalska KJ, Hansen JA, Bloomfield CD, Good RA. B lymphocytes in untreated patients with malignant lymphoma and Hodgkin's disease. J Clin Invest 1973;52: 3064-73.

${ }^{5}$ Gajl-Peczalska KJ, Bloomfield CD, Coccia PF, Sosin H, Brunning RD, Kersey JH. B and T cell lymphomas. Analysis of blood and lymph nodes in 87 patients. $A m$ J Med 1975;59:674-85.

${ }^{6}$ Nogachi S, Bukowski R, Deodhar S, Hewlett JS. T and B lymphocytes in non-Hodgkin's lymphoma. A comparison of tumour-derived cells and peripheral blood lymphocytes. Cancer 1976;37:2247-56.

${ }^{7}$ Filippa DA, Leiberman PH, Erlandson RA, et al. A study of malignant lymphomas using light and ultramicroscopic, cytochemical and immunological technics. Am $J \overline{\mathrm{O}}$ Med 1978;64:259-68.

${ }^{8}$ Garrett JV, Scarffe JH, Newton RK. Abnormal peripheral blood lymphocytes and bone marrow infiltration in non-Hodgkin's lymphoma. Br J Haematol 1979;42:41-50.

${ }^{9}$ Ligler FS, Vitetta ES, Smith RG, Himes JB, Uhr JW, Frenkel EP, Kettman JR. An immunologic approach for 0 the detection of tumour cells in the peripheral blood of $J$ patients with malignant lymphoma; implications for the diagnosis of minimal disease. J Immunol 1979;123:11236.

${ }^{10}$ Habeshaw JA, Stuart AE. Cell receptor studies on seven $\widetilde{N}$ cases of diffuse histoicytic malignant lymphoma (reti- $\mathrm{N}$ culum cell sarcoma). J Clin Pathol 1975;28:289-97.

11 Habeshaw JA, Young GA. Quantitation of subclasses of $\mathrm{N}$ mononuclear cells in normal human blood by membrane receptor studies. Br J Haematol 1975;29:43-55.

12 Burns J. Background staining and sensitivity of the unlabelled antibody-enzyme (PAP) method. Comparison $\mathbb{D}$ with peroxidase labelled antibody sandwich method using formalin fixed paraffin embedded material. Histochemistry 1975;42:291-4.

${ }^{13}$ Hunter CP, Tannenbaum H, Churchill WH, Moloney WC, Schur PH. Immunologic abnormalities in patients with malignant lymphoproliferative diseases. Journal of the National Cancer Institute 1977;58:1185-90.

14 Cabanillas F, Smith T, Bodey GP, Gutterman JU, Freireich, 
JM. Nodular malignant lymphomas. Factors affecting complete response rate and survival. Cancer 1979;44: 1983-9.

${ }^{15}$ Levy R, Warnke R, Dorfman RF, Haimovich J. The monoclonality of human B-cell lymphomas. J Exp Med 1977;145:1014-28.

16 Taylor CR. Immunohistologic studies of lymphomas. New methodology yields new information and poses new problems. J Histochem Cytochem 1979;27:1189-91.
${ }^{17}$ Isaacson $\mathrm{P}$, Wright DH. Anomalous staining patterns in immunohistologic studies of malignant lymphoma. $J$ Histochem Cytochem 1979;27:1197-9.

Requests for reprints to: Dr AS Krajewski, Department of Pathology, University Medical School, Teviot Place, Edinburgh EH8 9AG, Scotland

\section{Reports and Bulletins prepared by the Association of Clinical Biochemists}

The following reports and bulletins are published by the Association of Clinical Biochemists. They may be obtained from The Publishing Department, British Medical Journal (ACB Technical Bulletins), BMA House, Tavistock Square, London WC1H 9JR. Overseas readers should remit by British Postal or Money Order.

SCIENTIFIC REVIEWS (price $£ 1 \cdot 00 / \$ 2.00$ each)

1 The assessment of thyroid function March 1971 FV FLYNN and JR HOBBS

2 Renal function tests suitable for clinical practice January 1972 FL MITCHELL, N VEALL, and RWE WATTS

3 Biochemical tests for the assessment of fetoplacental function May 1975 CE WILDE and RE OAKEY

4 Test of exocrine pancreatic function March 1977 AH GOWENLOCK

5 Assay of cholinesterase in clinical chemistry March 1979 ELSIE SILK, J KING, and MARY WHITTAKER

TECHNICAL BULLETINS (price $£ 1 \cdot 00 / \$ 2.00$ each)

22 Bilirubin standards and the determination of bilirubin by manual and technicon AutoAnalyzer methods January 1971 BARBARA BILLING, RUTH HASLAM, and N WALD

23 Interchangeable cells for spectrophotometers and fluorimeters September 1971 SS BROWN and AH GOWENLOCK

24 Simple tests to detect poisons March 1972 BW MEADE et al.

25 Blood gas analysers May 1972 K DIXON

26 Kits for enzyme activity determination September 1972 SB ROSALKI and D TARLOW

27 Assessment of pumps suitable for incorporation into existing continuous flow analytical systems November 1972 A FLECK et al.

28 Routine clinical measurements of transferrin in human serum September 1973 K DIXON
29 Control materials for clinical biochemistry (5th edition) September 1973 JF STEVENS

30 Notes on the quality of performance of serum cholesterol assays September 1973 ss BROWN

31 Determination of uric acid in blood and in urine July 1974 RWE WATTS

32 A survey of amino acid analysers readily available in the United Kingdom September 1974 JE CARLYLE and P PURKISS

33 Definitions of some words and terms used in automated analysis November 1974 A FLECK, R ROBINSON, SS BROWN, and JR HOBBS

34 Measurement of albumin in the sera of patients January 1975 LINDA SLATER, PM CARTER, and JR HOBBS 35 Investigation of the validity of temperature correction factors for serum aspartate and alanine transaminases March 1975 SB ROSALKI et al.

36 Factors influencing the assay of creatinine November 1975 JGH COOK

37 A survey of enzyme reaction rate analysers readily available in the United Kingdom July 1977 RA SAUNDERS and RF BURNS

38 Transport of specimens for clinical chemistry analysis November 1977 P WILDING, JF ZILVA, and CE WILDE

39 A scheme for the evaluation of diagnostic kits May 1978 PH LLOYD

40 A practical guide to gamma-counting in radioimmunoassay January 1980 CE WILDE and D OTTEWELL 41 The use of biochemical tests in the diagnosis of disorders of calcium metabolism July 1980 ANGELA FAIRNEY 